\title{
Yenidoğanda İşitme Taramasının İzlenmesi
}

\author{
Ertuğrul YAVUZ*, Serdar SAĞSÖZLÜ**
}

\begin{abstract}
$\ddot{O} \mathbf{z}$
Zamanında teşhis edilememiş işitme kayıpları çocuğun ve ailesinin hayat kalitesini belirgin olarak bozar. Doğumsal işitme kaybı, dünyada en sık görülen doğumsal nörolojik problemdir. Sağlıklı yenidoğanda işitme kaybı oranı tüm dünyada binde 1-3 ve bizim ülkemizde binde 2,2 iken yenidoğan yoğun bakım ünitesinde izlenen bebeklerde bu oran \%1-6'dır. Yenidoğan işitme tarama izlemi için otoakustik emisyon (OAE) ve/veya işitsel beyin sapı cevabı (ABR) kullanılmaktadır. OAE testi, kokleanın dış tüylü hücrelerine kadar olan periferik işitsel sistem hakkında bilgi verirken, ABR testi periferik işitsel sistem, sekizinci sinir ve beyin sapının durumunu gösterir. Çocuklarda işitme kaybının erken teşhis ve yönetimi çok önemlidir. Yenidoğanlarda ilk bir ay içinde mutlaka işitme testi yapılıp ilk altı ay içinde uygun rehabilitasyon programları başlanmalıdır.
\end{abstract}

Anahtar Sözcükler: Yenidoğan yoğun bakımı, işitme kaybı, işitme taraması.

\section{Monitoring of Hearing Screening in Newborn}

\begin{abstract}
An undiagnosed hearing loss may have effect significantly child's and parents quality of life. Congenital hearing loss is one of the most common neurologic congenital problem in the world. For healty newborn, hearing loss rate is $1-3 / 1000$ for all over the world and 2,2/1000 in our country, but on the other hand for neonatal intensive care, this rate is 1-6/10o. Otoacustic emission (OAE) testing and/or auditory brainstem response (ABR) testing is used for neonatal

\section{Derleme Makale (Review Article)}

Geliş / Received: 07.11.2018 \& Kabul / Accepted: 15.11.2018

* Dr. Öğr. Üyesi, İstanbul Özel Yenibosna Safa Hastanesi, Kulak Burun Boğaz Kliniği, İstanbul, Türkiye ; İstanbul Gelişim Üniversitesi, Sağlık Bilimleri Yüksekokulu, Odyoloji Bölümü, İstanbul, Türkiye, E-posta: ertugrul_yavuz@yahoo.com, ORCID ID https://orcid.org/oooo0002-9378-1234

${ }^{* *}$ Dr. Öğr. Üyesi, İstanbul Özel Yenibosna Safa Hastanesi, Kulak Burun Boğaz Kliniği, İstanbul, Türkiye ; İstanbul Gelişim Üniversitesi, Sağlık Bilimleri Yüksekokulu, Odyoloji Bölümü, İstanbul, Türkiye, E-posta: sagsozlu@yahoo.com, ORCID ID https://orcid.org/oooo-00023058-6909
\end{abstract}


hearing screening program. While OAE testing informs about peripheral auditory system extending to the coclear outer hairy cells, ABR testing shows the status of the peripheral auditory system, eighth nerve and the brainstem. Early diagnosis and management of hearing loss in children is very important. By hearing tests should be performed in the first month of life and appropriate rehabilitation programs should be started in the first six months

Keywords: Neonatal intensive care, hearing loss, hearing tests.

\section{Giriş}

Yenidoğanlarda işitme kaybı, ebeveynler ve hekimler tarafından yeterli düzeyde fark edilemeyen bir durumdur ${ }^{1}$. Objektif işitme tarama testleri yapılmadığında; mevcut işitme kaybı, konuşmada gecikme olana dek belirti vermeyebilir. En sık görülen doğumsal nörolojik problem olarak bilinen doğumsal işitme kaybının sıklığı, zamanında gerçekleşen sağlıklı doğumlarda 1-3/1.00o olarak saptanmış olup bu oran prematüre doğumlarda ve herhangi bir sebepten dolayı riskli grupta yer alıp yenidoğan yoğun bakım ünitesinde (YYBÜ) takip edilen yenidoğanlarda \%1-6 olarak rapor edilmektedir²,3. İleri gebelik yaşı ve bebeğin düşük doğum ağırlığı gibi risk faktörlerinin varlığında işitme kaybı riski artmaktadır,5. Doğumsal işitme kaybının ülkemizdeki sıklı̆̆ı, zamanında doğan sağlıklı yenidoğanlarda 2,2/1000 iken, YYBÜ'de takip edilen bebeklerde \%1,4-2,9 olarak saptanmış olup risk faktörlerini taşıyan yenidoğanlarda bu oran daha yüksektir6,7. Doğumdan sonraki ilk aylarda işitmenin normal düzeyde olması; bebeğin dil gelişimi ve konuşması için önemlidir. Bunun yanında sosyoemosyonel gelişim, iletişim, kavrama, okuma ve zekâ gelişimi ile de bağlantılıdır. Yenidoğanlarda işitmenin değerlendirilmesi ve olası bir işitme kaybının saptanıp gerekli müdahalelerin zamanında yapılmaması halinde öncelikle dil gelişimi ve buna bağlı olarak konuşma, sosyal ve davranışsal gelişim çeşitli derecelerde etkilenmekte ve bu durum işitme kaybı olan çocukların yaşıtlarından geri kalmasına sebep olmaktadır ${ }^{8,9}$. Yaşamın ilk 6 ayında doğumsal işitme kaybı saptanan bebeklerle, 7 aydan sonra doğumsal işitme kaybı tanısı alıp gerekli girişimler yapılarak uygun görülen rehabilitasyon programına alınan bebekler karşılaştırıldığında; erken tanı alıp müdahale edilen bebeklerin, geç dönemde tanı alanlara göre dil gelişimleri, sosyal ve akademik başarılarının daha üst seviyede olduğu saptanmıştır ${ }^{8,10}$. Buradan yola çıkılarak, yenidoğanlarda işitme taramasının zamanında ve etkin bir şekilde yapılıp 
doğumsal işitme kayıplarının tespit edilmesi ve gerekli müdahale ve girişimlerin zamanında gerçekleştirilmesinin ne kadar önemli olduğu anlaşılmaktadır ${ }^{11,12}$. Bu nedenle olası bir işitme kaybının saptanması amacıyla yaşamın ilk 1 ayı içinde tüm bebeklerin işitme taraması yapılmalı ve 6. aydan önce gerekli rehabilitasyon programına başlanmalıdır ${ }^{3,9}$.

$\mathrm{Bu}$ çalışmada, yenidoğanlarda işitme taraması için kullanılan testler, uygulanma zamanları ve hangi yenidoğan grubuna uygulanacakları literatür eşliğinde tartışılmış olup yenidoğan işitme taramasının yönetilmesi hakkında güncel yaklaşımlar sunulmaya çalışılmıştır.

\section{İşitme Fizyolojisi ve İşitme Kayıplarının Sunıflandırılması}

İşitme, başın çevresinde oluşan ses dalgalarının dış, orta ve iç kulak aracılığı ile beyin sapından geçip korteksteki işitme merkezi tarafından algılanmasıdır. Normal işitmede aurikula tarafından toplanan ses dalgaları, dış kulak yolu ile kulak zarına iletilerek zarda bir titreşime neden olur. Oluşan titreşim, orta kulak kemikçikleri aracıllı̆ıyla stapes tabanındaki oval pencereden iç kulağa aktarılır ve scala vestibuli içindeki perilenfte harekete neden olur. Bu dalga hareketi scala timpaniye iletilerek yuvarlak pencereyi örten membranda orta kulağa doğru bombeleşme yapar. Ses basıncının kemikçikler aracılığıyla scala vestibuliye ulaştırılması ve yuvarlak pencereyi örten zarın oval pencereye göre esneklik farkı, scala vestibuli ile scala timpani arasında basınç farkı oluşturur. Bu basınç farkı, korti organındaki dış ve iç tüylü hücrelerde bir stereosiliyal harekete sebep olmaktadır. Koklea pasif bir organ değildir. Dış tüylü hücrelerin ses üretebilme kapasiteleri vardır ve bu sese “otoakustik emisyon (OAE)” denmektedir. İç tüylü hücreler ise oluşan mekanik enerjiyi elektriksel stimulusa çevirir ve akustik nöronların dendritleri uyarılır. Bu sinir hücrelerinin aksonları sekizinci sinirin koklear dalını oluşturup elektriksel aktiviteyi beyin sapına iletir. Bu elektriksel aktivite, ponstaki dorsal ve ventral koklear çekirdeklerden lateral lemniskus, superior oliver kompleks ve inferior kollikulusa iletilir. Buradan talamustaki medial genikulat cisimciğe iletilen elektriksel aktivite, temporal korteksteki işitme merkezine ulaşınca ses algısı oluşmaktadır. Kokleada dış tüylü hücrelerin ürettiği ses, yuvarlak pencere aracılığıyla orta kulak boşluğu, kemikçikler ve kulak zarından geçip dış kulak yoluna geri gelir ve bu sese otoakustik emisyon denir ${ }^{12}$. OAE testi ile işitmenin 
değerlendirilmesinin esası, kokleanın ürettiği bu seslerin dış kulak yolunda kaydedilmesidir. İşitme kayıpları dört ana grupta sınıflandırılır9,12.

\section{İşitme Kayıpları Tipleri}

\section{1. İletim Tipi İşitme Kaybı}

Dış veya orta kulaktan kaynaklanan nedenlerle ses iletiminin bozulmasıdır. Geçici (buşon, yabancı cisim, dış kulak iltihapları, kulak zarı perforasyonu, otitis media) veya kalıcı (kulak kepçesi yokluğu veya şekil bozukluğu, dış kulak yolunun doğuştan kapalı olması) nedenlerden dolayı oluşabilir.

\section{Sensörinöral İşitme Kaybı}

İç kulak, koklear sinir, koklear nukleus ve kortikal işitme merkezi patolojilerinde görülür.

\section{Nöral İşitme Kaybı}

Kokleadaki dış tüylü hücreler sağlamken iç tüylü hücreler, koklear sinir ve nöronal ileti yolundaki bozuklukları içermektedir.

\section{Mikst Tip İşitme Kaybı}

İletim tipi ve sensörinöral veya nöral işitme kayıplarını içermektedir ${ }^{12}$.

\section{İşitme Kaybı Risk Faktörleri}

1. Aile öyküsü

2. YYBÜ'de 5 günden fazla kalma veya ototoksik ilaç kullanımı, loop diüretiği kullanımı ya da kan transfüzyonu gerektirecek hiperbilirubinemi varlığı

3. Enfeksiyonlar: TORCH (intrauterin enfeksiyonlar), bakteriyel veya viral menenjit, en az üç ay süren tekrarlayan otitis media veya effüzyonlu otitis media

4. Kraniofasial anomaliler

5. İşitme kayıplarının eşlik ettiği sendromlar

6. Sensörinöral nöropatiler ve nörodejeneratif hastalıklar

7. Çeşitli şiddetlerde kafa travmaları 


\begin{abstract}
8. Kemoterapi
9. Prematurite

10. İntrakranial kanama

11. Çok düşük doğum ağırlığı (1500 gr altı)13-16.
\end{abstract}

Normal işitmeye sahip yenidoğanlar o-15 desibel (dB) şiddetindeki sesi işitebilirken, 15 dB'den fazla şiddetteki seslerin işitilmemesi çeşitli derecelerde işitme kaybı olarak kabul edilmekte ve kaybın derecesine göre konuşma, anlama, kavrama ve dil gelişiminde bozukluklar ortaya çıkabilmektedir. Buna bağlı olarak işitme kaybının derecesi ilerledikçe işitme cihazı, işitsel ve konuşma terapisi ihtiyacı, ayrıca özel eğitim gereksinimi doğmaktadır ${ }^{9,17}$.

Doğumsal işitme kayıplarının en büyük kısmını \%50,8 ile idiyopatik nedenler, \%33,3'ünü genetik olmayan nedenler, \%15,8'lik kısmını ise genetik nedenler oluşturmaktadır. Genetik olmayan işitme kaybı nedenleri arasında gebelik toksemisi, ototoksik ilaç kullanımı, enfeksiyonlar, sarılık ve Rh uyuşmazlığı, düşük Apgar skoru, düşük doğum ağırlığı, hiperbilirubinemi ve serebral palsi gösterilebilir. Genetik işitme kayıplarının \%10,8'i ailesel olup \%12,5 konjenital sendromlarla ilişkili bulunmuştur. Ülkemizdeki doğumsal işitme kayıplarının ise \%51'inin genetik, \%34'ünün idiyopatik, \%15'inin ise edinsel nedenlerden kaynaklandığı saptanmıştır9,18.

Bunun yanında, doğumsal işitme kaybı saptanan bebeklerin \%90-95'inde ailede işitme kaybı olmayıp \%53,6'sında herhangi bir risk faktörü bulunmadığı tespit edilmiştir8,10.

\title{
Işitme Taramasında Kullanılan Testler
}

Yenidoğanlarda işitme taramasında, uyarılmış OAE ve otomatik işitsel beyin sapı yanıtı (otomatik ABR) testleri kullanılmaktadır. Her iki testin de otomatik olması, uygulama kolaylığı, invaziv işlem gerektirmemesi gibi ortak özellikleri vardır. Bu testler ayrı ayrı veya birarada uygulanabilmektedir. Uygulama zamanı olarak ilk 24 saatte yapılması idealdir ${ }^{19,20}$.

\section{Otoakustik Emisyon}

Bu testin esası, kokleanın ürettiği seslerin dış kulak yolunda kaydedilmesine dayanır. Koklea pasif bir organ değildir, dış tüylü hücrelerin akustik enerji üretme kapasiteleri 
vardır. Kokleanın ürettiği bu seslere otoakustik emisyon denir ve bu ses orta kulak boşluğu, kemikçikler ve timpanik membrandan geçerek dış kulak yoluna yerleştirilen bir mikrofon ile kaydedilir. Kaydedilen sesler amplifiye edilip dijitale dönüştürülerek analiz edilir. Koklear yanıtın olup olmadığına göre "kaldı" veya "geçti” şeklinde sonuç verilir3.

Şekil 1: Otoakustik emisyon (OAE) testi şematik görünümü

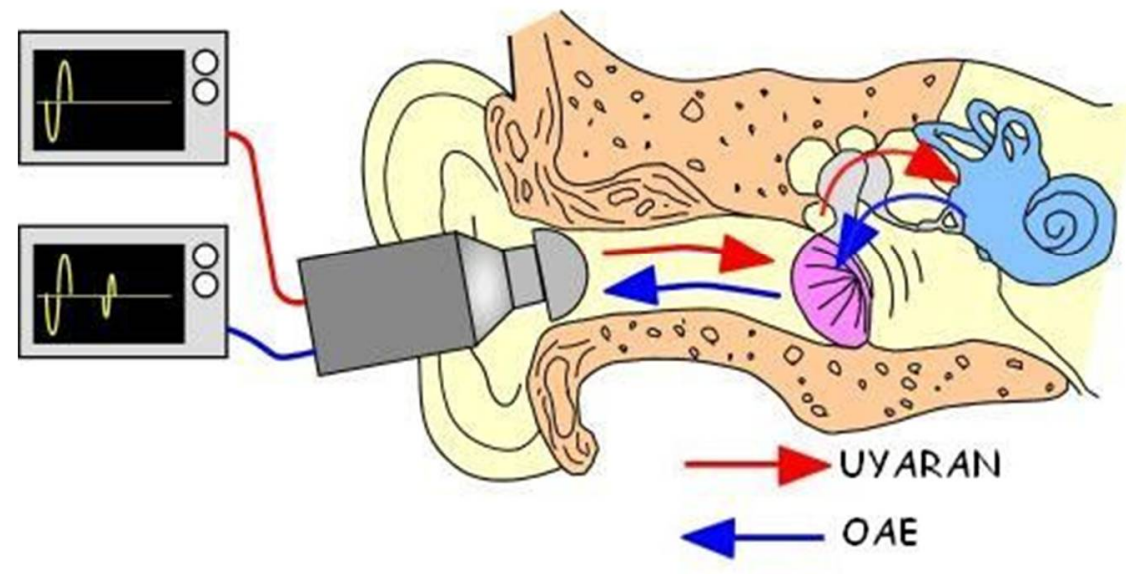

Kokleaya hiçbir sesli uyaran vermeden elde edilen emisyonlara spontan OAE denir ve normal kokleaların \%40-6o'ında saptanır. 40 dB'den fazla koklear işitme kaybı olanlarda spontan OAE görülmez. Akustik uyaran verilerek elde edilen OAE'lara uyarılmış OAE denir ve farklı uyaran tiplerine göre; transient evoked OAE (TEOAE), stimulus frekans OAE (SFOAE) ve distortion product OAE (DPOAE) olarak üç türü vardır. TEOAE, normal işiten kişilerde \%98 oranında saptanır ve 30-40 dB üzerindeki sensörinöral işitme kayıplarında alınamaz, koklear fonksiyonlar için tarama testi olarak kullanılır3,21. SFOAE, sürekli saf ses sinyali ile ortaya çıkar ve ölçümü kolay değildir. DPOAE, iki veya daha fazla frekansta saf sesin aynı anda verilmesiyle ortaya çıkar ve her bir frekans için ayrı ayrı inceleme gereksinimi, testin süresini uzatmakta olup testin değerlendirilmesi uzmanlık gerektirmektedir²1.

Yenidoğanlarda işitme taramasında en sık kullanılan test TEOAE olup kolay uygulanabilirliği, premedikasyon veya anestezi gerektirmemesi, objektif ve hızlı sonuç alabilme ve yanlış pozitifliğin düşük olması nedeniyle tercih edilmektedir ${ }^{22}$. 
Dış kulak yolunu tıkayan buşon veya sıvı varlığında, kanalın dar olması halinde, orta kulakta sıvı birikmesi ve kulak zarı rahatsızlıklarında, ayrıca dış tüylü hücre hasarında OAE alınamaması testin dezavantajlarıdır³,21.

\section{Işitsel Beyin Sapı Cevabı (ABR)}

Duysal bir uyaranın beyin sapına kadarki oluşan uyarılmış potansiyelleridir. Bunlar baş bölgesine yerleştirilen elektrotlarla kaydedilir3,21. Yedi dalga tipi olmasına rağmen her zaman görülmese de I, III ve V. dalganın normal işitenlerde izlenmesi gerekir. $\mathrm{Bu}$ dalgalar karmaşık bir sistemle oluşsa da genel kabule göre; koklear sinirin alt bölümü I. dalga, üst bölümü II. dalga, bulbus III. dalga, üst oliver kompleksi IV. dalga, lateral lemniskus ve inferior kollikulus V. dalga, mediyal genikulat çekirdek ve alt kollikulus ise VI. ve VII. dalgaları oluşturur ${ }^{21,23}$.

OAE testine kıyasla ABR testi daha pahalı olmakla beraber yanlış pozitiflik oranı çok daha düşük olup yaklaşık \%o,25 civarındadır. Buna karşın ABR testi dış etkilerden ve hareketten etkilenebileceği için zaman zaman premedikasyon lüzumlu olabilir3,19,21.

\section{İşitme Taraması Yönetimi}

İşitme taramasında sağlık kuruluşları basamaklara ayrılmış olup birinci basamakta sadece OAE veya beraberinde ABR, ikinci basamakta mutlaka ABR kullanılmalıdır. İkinci basamak sağlık kuruluşunda yapılan tetkikler sonucunda başarısız olanlar üçüncü basamağa (referans merkez) yönlendirilir.

Üçüncü basamakta mutlaka bir KBB uzmanı, odyolog, odyometrist ve yeterli ekipman bulunmalıdır²2.

Her iki yöntemde de teşhis noktasında bazı zorluklar vardır. Mesela 40 dB'den daha az işitme kayıplarında veya sonradan gelişmiş işitme kayılarında teşhis konulamayabilir ${ }^{1,9,24}$.

Bununla birlikte özellikle YYBÜ'ne girmek zorunda kalmış bebeklerde mutlaka ABR yapılması hem teşhis kesinliği ve hem de hızlı teşhis koyabilmek için gereklidir,12,24.

Bütün yenidoğanların ilk işitme taraması doğumun yapıldı̆̆ı merkezde mutlaka yapılmalıdır. İdeal olan, testlerin doğumdan 24 saat geçmeden, bebek tok bir halde ve doğal uyku halinde iken yapılmasıdır ${ }^{24}$. Taramadan geçemeyenler yaklaşık bir hafta 
sonra bir kez daha taranırlar. Taramanın her iki kulağa da yapılması önemlidir zira iki taraflı işitme kayıpları yaklaşık binde 1,6 iken tek taraflı işitme kayıpları binde 0,5 olarak belirtilmektedir3,19,25.

Bebeğin tarama test sonuçları mutlaka sağlık bakanlığı ilgili birimine bildirilmelidir. Risk olmayan yenidoğanda teste OAE ile başlanıp bebek testi geçemezse bir hafta sonra test tekrarlanır, yine geçemezse ABR yapılır. Bu testten de geçemezse referans merkeze yollanır. Risk olan yenidoğanlarda ise direkt ABR yapılır. Bebek testi geçemezse test tekrarlanır, yine geçemezse referans merkeze yollanır²2.

\section{Sonuç}

İşitme kaybının çocukların iletişim, kavrama, okuma ve sosyal gelişimlerinde geriliğe neden olduğu bir gerçektir ${ }^{22}$. Önerilen yaklaşım, çocukların işitme durumlarının doğumdan itibaren 1.ay içinde ortaya konması için tarama testlerinin yapılması ve bu süreçlerde testlerden geçemeyen bebeklerin 6. aydan itibaren uygun rehabilitasyon programlarına dahil edilmesidir3,11,12. Doğumsal işitme kaybı, konuşmada gecikme olana kadar fark edilmesi zor bir durum olduğu için, yenidoğanlarda işime taramasının önemi son derece fazladır. İşitme kaybı olan çocuklarda tedaviye geç kalınması durumunda, çocuğun ve ailenin yaşam standartlarının maddi ve psikolojik olarak ciddi boyutlarda etkilendiği, bu ve benzer sorunların hem bireysel hem de toplumsal yaşam kalitesinin artırılması için ivedilikle çözüme kavuşturulmasının önemi aşikârdır.

\section{KAYNAKLAR}

1. Chu K, Elimian A, Barbera J, Ogburn P, Spitzer A, Quirk JG. Antecedents of newborn hearing loss. Obstet Gynecol. 2003;101(3):584-588.

2. Bernbaum JC. Medical care after discharge. In: Avery GB, MacDonald MG, Seshia MMK, eds. Avery's Neonatalogy, Pathophysiology and Management of the Newborn. 7. ed. Philadelphia: Wolters Kluver; 2016.

3. American Academy of Pediatrics, Joint Commitee on Infant Hearing. Year 2007 position statement: Principles and guidelines for early hearing detection and intervention programs. Pediatrics. 2007;120(4):898-921.

4. van Dommelen P, Verkerk PH, van Straaten HL; Dutch Neonatal Intensive Care Unit Neonatal Hearing Screening Working Group. Hearing loss by week of 
gestation and birth weight in very preterm neonates. $J$ Pediatr. 2015;166(4):840-843. doi: 10.1016/j.jpeds.2014.12.041.

5. T.C. Başbakanlık Özürlüler İdaresi-Bilgi İşlem Dairesi Başkanlığı. Ulusal Yeni doğan İşitme Projesi; 2005. http://www.ozida.gov.tr/projeler/işitmetaraması.htm. Erişim tarihi 10 Ekim 2018.

6. Bolat H, Bebitoglu FG, Ozbas S, Altunsu AT, Kose MR. National newborn hearing screening program in Turkey: Struggles and implementations between 2004 and 2008. Int J Pediatr Otorhinolaryngol. 2009;73(12):1621-1623. doi: 10.1016/j.ijporl.2009.08.002.

7. Arslan S, Işik AU, Imamoğlu M, Topbaş M, Aslan Y, Ural A. Universal newbornhearing screening; automated transient evoked otoacustic emmissions. $B$-ENT. 2013;9(2):122-131.

8. Sugaya A, Fukushima K, Kasai N, et al. Impact of early intervention on comprehensive language and academic achievement in Japanese hearing impaired children with cochlear implants. Int J Pediatr Otorhinolaryngol. 2015;79(12):2142-2146.doi: 10.1016/j.ijporl.2015.09.036.

9. 9.Özdemir Ö, Tümkaya F. Yeni doğanda işitme tarama programı ve yönetimi. Türkiye Klinikleri J Pediatr. 2017;26(1):13-21. doi: 10.5336/pediatr.201652330 .

10. Genç GA, Barmak E. The effect of newborn hearing screening on the development of newborns with congenital hearing loss. Türkiye Klinikleri $J$ Med Sci. 2012;32(5):1284-94.

11. Bolat H, Genç GA. National newborn hearing screening in Turkey; history and principles. Türkiye Klinikleri J E.N.T.-Special Topics. 2012;5(2):11-14.

12. Vohr B. Hearing loss in the newborn infant. In: Martin RJ, Fanaroff AA, Wals MC, eds. Fanaroff and Martin's Neonatal-Perinatal Medicine Diseases of the Fetus and Infant. 10. ed. Philadelphia: Elsevier Saunders: 2015.

13. Jakubikova J, Kabatova Z, Pavlovcinova G, Profand M. Newborn hearing screening and strategy for early detection of hearing loss in infants. Int Journal of Pediatric Otorhinolaryngology. 2009;73(4):607-612. doi: 10.1016/j.ijporl.2008.12.006. 
14. Korres S, Nikolopoulos TP, Komkotou V, et al. Newborn hearing screening: Effectiveness, importance of high risk factors, and characteristics of infants in the neonatal intensive care unit and well-baby nursery. Otolog \&Neurotology. 2005;26(6):1186-1190. doi: 10.1097/o.mao.0000184602.94677.41.

15. Drela M, Korbal P, Sinkiewicz A, Szulczynski J. The examinations of hearing in infants treated in neonatal intensive care units. Otolaryngol Pol. 2002;56(5):611-616.

16. Hille ET, van Straaten HI, Verkerk PH; Dutch NICU Neonatal Hearing Screening Working Group. Prevalence and independent risk factors for hearing loss in NICU infants. Acta Pediatrica. 2007;96(8):1155-1158. doi: 10.1111/j.16512227.2007.00398.x.

17. Williams TR, Alam S, Gaffney M. Progress in identifying infants with hearing loss-United States, 2006-2012. MMWR Morb Mortal Wkly Rep. 2015;64(13):351-356.

18. Declau F, Boudewyns A, Van den Ende J, Peeters A, van den Heyning P. Etiologic and audiologic evaluations after universal neonatal hearing screening: analysis of 170 referred neonates. Pediatrics. 2008;121(6):1119-1126.

19. Choo D, Meinzen-Derr J. Newborn hearing screening in 2010. Curr Opin Otolaryngol Head Neck Surg. 2010;18(5):399-404. doi: 10.1097/MOO.obo13e32833d475d.

20. Rowe A, Gan R, Benton C, Daniel M. Screening for hearing loss in children. Pediatr ChildHealth. 2016;26(1):26-30.

21. Şerbetçioğlu B, Gürkan S, Mungan S. Clinical importance and application principles of ABR and OAE tests. Türkiye Klinikleri J E.N.T. -Special Topics. 2012;5(2):51-61.

22. Öner S, Şiraneci R, Kavuncuoğlu S, Ramoğlu M. Yenidoğan Yoğun Bakım Ünitesinde İzlenen Riskli Yenidoğanların İki Basamaklı İşitme Taramasıyla Değerlendirilmesi. JOPP Derg. 2010;2(1):35-39.

23. Kenna MA. Neonatal hearing screening. Pediatr Clin North Am. 2003;50(2):301-313.

24. Ozturk O, Silan F, Oghan F, et al. Evaluation of deaf children in a large series in Turkey. Int J Otorhinolaryngol. 2005;69(3):367-373. doi: 10.1016/j.ijporl.2004.11.001. 
25. T.C Ministry of Health, Turkish Public Health Institution, Department of Child and Adolescent Health. Ulusal Yenidoğan İşitme Taraması Uygulama Rehberi. 2014. https://www.saglik.gov.tr/TR/turkiye-halk-sagligi-kurumu.html. Erişim tarihi 10 Ekim 2018. 